\title{
Micro Total Analysis System Application for Biomedicals: A Mini-Review
}

\author{
Yehezkiel Steven Kurniawan* \\ Ma Chung Research Center for Photosynthetic Pigments, Universitas Ma Chung, Villa Puncak Tidar N-01, Malang 65151, East Java, Indonesia
}

Received: 制: December 15, 2018; Published: 制: January 03, 2019

*Corresponding author: Yehezkiel Steven Kurniawan, Ma Chung Research Center for Photosynthetic Pigments,Universitas Ma Chung, Indonesia

\begin{abstract}
Recently, the microfluidic system is one of the most trending research topics in the world due to its unique characteristics and great advantages. The present mini-review deals with the application of micro total analysis system for the biomedical fields, such as in situ detection, enrichment, imaging, and quantification of biomolecules and cell. The recent progress of the microfluidic system on cancer, tumor, HIV, diabetes, malaria and tuberculosis was displayed.
\end{abstract}

Keywords: Microfluidic; Micro Total Analysis System; Biomedical Application

\section{Introduction}

Microfluidic is a new field which employing reactor channels in micrometer dimensions [1,2]. The first primitive microfluidic study was introduced by Hodgson and Charles in 1963. They investigated the slug flow between water and oil in pipe and studied for their flow pattern, droplet velocity and pressure drop inside the pipe [3]. In 2001, Burn and Ramshaw reported the mass transfer phenomena of acetic acid from the aqueous phase to the kerosene as the dispersed phase [4]. From 2001, a lot of papers related to microfluidic study and application have been published. Even though this system called as micro total analysis device, it is possible to set up a system that includes sampling, pre-treatment, sensor/detection, quantification and imaging process as called as micro total analysis system or lab-on-chip system [5]. This unique and marvelous application is possible because of the great advantages from employing the microfluidic system. The advantages from employing microfluidic system are portable device, tiny chemical reagents are required, save energy and space, rapid and easy control process and low-risk operation [6]. Therefore, great interests are on the microfluidic field due to its unique characteristics and phenomena. Microfluidic system has been widely applied in metal extraction, organic synthesis and biomedical fields such as rapid and in situ detection and monitoring of biochemicals, enzymatic reaction, drug screening and delivery, cell assay, protein crystallization, and so on [7-14]. The present mini review is focused on micro total analysis system for biomedical application and the progress on the recent researches are briefly discussed.
Cancer is one of the most concerned diseases in the world. Many researchers are trying to make significant findings to detect and treat the cancer cells, however, the conventional method is time-consuming, low validity, and lack appropriate control [15]. Microfluidic system offers a real-time and reliable analysis to detect the cancer cell in the in vitro and in vivo study [16]. Bhagat, et al. reported the isolation of cancer cell from the blood by employing lift force-induced cell separation technique in well-design microchannels. By using this technique, the recovery percentage of circulating tumor cell reached $81 \%$ with 20 times sample dilution and $0.400 \mathrm{~mL} / \mathrm{min}$ sample flow rate (around 108 cells $/ \mathrm{min}$ ), which is rapid and efficient separation compared with conventional technique [17]. On the other hand, microfluidic applications on tumor cell were also reported. Moore, et al. evaluated a multiplexed microfluidic system to monitor the immune-tumor interactions. The established system is able for imaging of autologous TILs and tumor fragments in a real-time analysis for several days [18].

Besides of cancer and tumor, Human Immunodeficiency Virus (HIV) infection creates a serious problem on human health. Therefore, preliminary detection is highly required to prevent further infection. HIV detection by imaging process using two-color Qdot525 and Qdot655 streptavidin conjugates which are able to interact with the gp120 glycoprotein and its mannose glycans was reported by Kim et al. [19]. Insulin detection for diabetic treatment was reported by Yao, et al. by employing microbeads based on 
double-antibody sandwich immunoassay coupled with luminal$\mathrm{H}_{2} \mathrm{O}_{2}$ chemiluminescence. The limit of detection for insulin reached $0.4 \mathrm{nmol} / \mathrm{L}$ by this device, which meets the requirement for diabetic clinical study [20]. Other microfluidic applications for malaria and tuberculosis disease were also reported. Malarial detection by using shear-modulated inertial microfluidic system was reported by Warkiani, et al. and it was found that the microfluidic device is 100 times more sensitive than the gold-microscopy standard technique to detect the malarial parasites [21]. Microfluidic device to directly capture and analysis the air bone contains Mycobacterium tuberculosis has been developed [22]. By using this developed device, the detection time including enrichment and immunoreaction analysis was less than $1 \mathrm{~h}$, which is remarkably improved compared with the conventional methods.

\section{Conclusion}

Micro total analysis system offers the recent world for an easy handling, real-time, and integrated system in the biomedical fields. Due to its unique characteristics, a lot of pivotal applications on cancer, tumor, HIV, diabetes, malaria and tuberculosis have been reported. By integrating each application, it is possible to transform the micro total analysis system to organ-on-a-chip or human-bodyon-a-chip. The author believes that in near future, a well design and compact biological device based on the microfluidic system will be available and commercialized.

\section{References}

1. Wang K, Luo G (2017) Microflow extraction: A review of recent development. Chem Eng Sci 169: 18-33.

2. Jensen KF (2017) Flow chemistry - microreaction technology comes of age. AIChE J 63(3): 858-869.

3. Hodgson GW, Charles ME (1963) The pipeline flow of capsules: Part 1: The concept of capsule pipelining. Can J Chem Eng 41(2): 43-45.

4. Burn JR, Ramshaw C (2001) The intensification of rapid reactions in multiphase systems using slug flow in capillaries. Lab Chip 1: 10-15

5. Huebner A, Sharma S, Srisa Art M, Hollfelder F, Edel JB, et al. (2008) Microdroplets: A sea of applications? Lab Chip 8(8): 1244-1254.

6. Zhang J, Wang K, Teixeria AR, Jensen KF, Luo G (2017) Design and scalling up of microchemical system: A review. Annu Rev Chem Biomol Eng 8: 285-305.

7. Sathuluri RR, Kurniawan YS, Kim JY, Maeki M, Iwasaki W, et al. (2017) Droplet-based microreactor system for stepwise recovery of precious metal ions from real metal waste with calix[4]arene derivatives. Sep Sci Technol 53(8): 1261-1272.

\section{ISSN: 2574-1241}

DOI: $10.26717 /$ BJSTR.2019.12.002294

Yehezkiel Steven Kurniawan. Biomed J Sci \& Tech Res

This work is licensed under Creative Commons Attribution 4.0 License

Submission Link: https://biomedres.us/submit-manuscript.php
8. Kurniawan YS, Sathuluri RR, Iwasaki W, Morisada S, Kawakita H, et al. (2018) Microfluidic reactor for $\mathrm{Pb}(\mathrm{II})$ ion extraction and removal with an amide derivative of calix[4] arene supported by spectroscopic studies. Microchem J 142: 377-384.

9. Kurniawan YS, Sathuluri RR, Ohto K, Kawakita H, Morisada S, et al. (2019) A rapid and efficient lithium-ion recovery from seawater with tripropyl-monoacetic acid calix[4]arene derivative employing dropletbased microreactor system. Sep Purif Technol 211: 925-934.

10. Kurniawan YS, Ryu M, Sathuluri RR, Iwasaki W, Morisada S, et al. (2018) Separation of $\mathrm{Pb}(\mathrm{II})$ ion with tetraacetic acid derivative of calix[4]arene by using droplet-based microreactor system. Indones J Chem In press.

11. Hassan AA, Sandre O, Cabuil V (2010) Microfluidics in inorganic chemistry. Angew Chem Int Ed 49(36): 6268-6286.

12. Kaminski TS, Garstecki P (2017) Controlled droplet microfluidic systems for multistep chemical and biological assays. Chem Soc Rev 46(20): 6210-6226.

13. Busa LSA, Mohammadi S, Maeki M, Ishida A, Tani H, et al. (2016) Advances in microfluidic paper-based analytical devices for food and water analysis. Micromachines 7(5): 86.

14. Maeki M, Yamashita S, Pawate AS, Ishida A, Tani H, et al. (2016) A microfluidic-based protein crystallization method in 10 micrometersized crystallization space. Cryst Eng Comm 18(40): 7722-7727.

15. Chin CD, Laksanasopin T, Cheung YK, Steinmiller D, Linder V, et al. (2011) Microfluidics-based diagnostics of infectious diseases in the developing world. Nat Med 17(8): 1015-1019.

16. Faustino V, Catarino SO, Lima R, Minas G (2016) Biomedical microfluidic devices by using low-cost techniques: A review. J Biomech 49(11): 22802292.

17. Bhagat AAS, Hou HW, Li LD, Lim CT, Han J (2011) Pinched flow coupled shear-modulated inertial microfluidics for high-throughput rare blood cell separation. Lab Chip 11(11): 1870-1878.

18. Moore N, Doty D, Zielstorff M, Kariv I, Moly LY, et al. (2018) A multiplexed microfluidic system for evaluation of dynamics of immune-tumor interactions. Lab Chip 18(13): 1844-1858.

19. Kim YG, Moon S, Kuritzkes DR, Demirci U (2009) Quantum dot-based HIV capture and imaging in a microfluidic channel. Biosens Bioelectron 25(1): 253-258.

20. Yao P, Tung S, Zhan Z, Hua J, Dong Z (2012) Development of microfluidicbased telemedicine for diabetes care and screening. T I Meas Control 35(7): 893-900.

21. Warkiani ME, Tay AK, Khoo BL, Xiaofeng X, Han J, et al. (2015) Malaria detection using inertial microfluidics. Lab Chip 15(4): 1101-1109.

22. Jing W, Jiang X, Zhao X, Liu S, Cheng X, et al. (2014) Microfluidic platform for direct capture and analysis of airborne Mycobacterium tuberculosis. Anal Chem 86(12): 5815-5821.

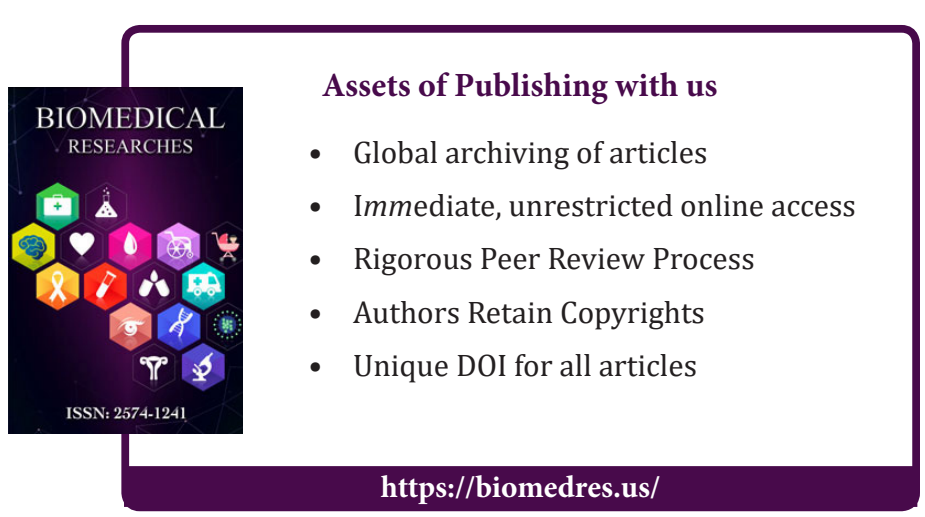

